\title{
Formação docente e identidade profissional: tensões e (des)continuidades
}

\author{
Teacher education and professional identity: \\ tensions, continuities and discontinuities
La formación del profesorado y de la identidad profesional: tensiones $y$ (dis)continuidades

MARIA ASSUNÇÃO FLORES*

\begin{abstract}
RESUMO - Neste artigo discutimos o conceito de identidade profissional à luz da literatura internacional sobre esta temática e apresentamos alguns resultados de um estudo em curso que visa compreender o modo como os alunos veem o currículo da formação inicial, com especial destaque para o lugar da prática na configuração da sua identidade profissional, bem como as suas motivações, crenças e perspetivas futuras sobre a profissão docente e sobre ser professor. O texto termina com uma reflexão sobre o desenvolvimento da identidade profissional na formação inicial de professores, nomeadamente a partir da compreensão e questionamento de crenças, valores e imagens pessoais sobre o ensino e sobre o que significa tornar-se (e ser) professor, bem como sobre o próprio processo de formação e de (re)construção de saberes, através da reflexão e da indagação em articulação com a prática.
\end{abstract}

Palavras-chave - Identidade profissional. Alunos. Formação docente.

\begin{abstract}
This paper discussed the concept of professional identity in the light of existing international research literature on the topic. It presents the major findings from ongoing research aiming at understanding the ways in which student teachers look at the various components of the curriculum of initial teacher education, particularly the role of practicum in the configuration of their professional identity as well as their motivations, beliefs and future perspectives about teaching and being a teacher. The paper ends with a reflection about the development of the professional identity in initial teacher education namely in terms of the understanding and questioning of beliefs, values and personal images about teaching and becoming a teacher and the training process as well as the (re)construction of knowledge, through reflection and inquiry about practice.
\end{abstract}

Keywords - Professional identity. Student teachers. Teacher education.

RESUMEN - En este trabajo se analiza el concepto de la identidad profesional a la luz de la literatura internacional sobre este tema y presentar algunos resultados de un estudio en curso que tiene como objetivo estudiar cómo los estudiantes entendían el programa de formación, con especial énfasis en el lugar de la práctica en el establecimiento de su identidad profesional y sus motivos, creencias y perspectivas de futuro de la profesión docente y de ser profesor. El texto finaliza con una reflexión sobre el desarrollo de la identidad profesional en formación inicial del profesorado, en particular, de la comprensión y el cuestionamiento de las creencias, los valores y las imágenes personales sobre la enseñanza y sobre lo que significa llegar a ser (y ser) maestro, así como el proceso de formación y la (re)construcción de conocimientos a través de la reflexión y de la investigación en relación con la práctica en sí misma.

Palabras clave - Identidad profesional. Estudiantes. Formación del professorado.

\footnotetext{
* Doutora em Educação pela Universidade de Nottingham (Nottingham, Inglaterra) e professora na Universidade do Minho (Braga, Portugal). E-mail:<aflores@ie.uminho.pt>.
} 


\section{INTRODUÇÃO}

A investigação sobre o processo de aprender a ensinar tem atraído um grande número de investigadores ao longo das últimas décadas, no sentido de compreender a passagem de aluno a professor e de professor principiante a professor experiente. Aprender a ensinar não se reduz à mera aplicação de um conjunto de técnicas e destrezas; implica também a construção de conhecimento e de sentido num diálogo permanente com a prática (FLORES, 2004).

Tornar-se professor constitui, por isso, um processo multidimensional, idiossincrático e contextual (CALDERHEAD; SHORROCK, 1997; FLORES, 2001; FLORES; DAY, 2006; HAUGE, 2000) que implica a articulação entre diferentes, e por vezes conflituais, perspetivas, crenças e práticas. Assim, é essencial compreender o sentido de identidade na aprendizagem dos alunos em formação inicial e no modo como estes se desenvolvem como profissionais no contexto da prática.

Neste texto discutimos o conceito de identidade profissional à luz da literatura internacional sobre esta temática e apresentamos alguns resultados de um estudo em curso que visa compreender o modo como os alunos veem a sua formação inicial, com especial destaque para o lugar da prática na configuração da sua identidade profissional, bem como as suas motivações, crenças e perspetivas futuras sobre a profissão docente e ser professor.

\section{A IDENTIDADE PROFISSIONAL: CONCEITO(S) E PROCESSO DE DESENVOLVIMENTO}

O estudo da identidade dos professores desenvolveuse como área de investigação específica nas duas últimas décadas (BEIJAARD; MEIJER; VERLOOP, 2004; PILLEN; BEIJAARD; DEN BROK, 2012). Para Sachs (2001a), a identidade docente constitui um processo negociado, aberto e em mutação que "é mediado pela sua [dos professores] experiência nas escolas e fora delas e pelas suas próprias crenças e valores sobre o que significa ser professor e o tipo de professor que aspiram vir a ser" (2001a, p. 154). Assim, a identidade profissional não é uma entidade estável ou fixa ou ainda um produto, é "um lugar de lutas e de conflitos" e "um espaço de construção de maneiras de ser e de estar na profissão" (NÓVOA, 1992, p. 16).

O termo identidade encerra vários sentidos que têm sido utilizados na investigação, tal como identificaram Beijaard, Meijer e Verloop (2004) na sua revisão de estudos sobre esta temática. Esses autores categorizaram os estudos em três tipos: (i) os que se centram na formação da identidade profissional dos professores; (ii) os que investigam as características da identidade profissional e (iii) aqueles em que a identidade profissional é representada (e apresentada) através das histórias dos professores. Os mesmos autores salientam que emerge destes estudos a ideia comum de que a identidade não constitui "um atributo fixo de uma pessoa, mas um fenómeno relacional" (BEIJAARD; MEIJER; VERLOOP, 2004, p. 108), também entendido como "autocompreensão" (KELCHTERMANS, 2005).

A identidade profissional desenvolve-se na interação entre o indivíduo e o ambiente ou o contexto (KORTHAGEN, 2004; BEIJAARD; MEIJER; VERLOOP, 2004) e encerra a análise da natureza das relações entre as estruturas sociais e a agência individual (DAY et al., 2006). Como argumenta Sachs (2001a, p. 15), a identidade "constitui o âmago da profissão docente. Ela proporciona um quadro de referência para os professores construírem as suas próprias ideias sobre 'como ser' professor, 'como agir' e 'como compreender' o seu trabalho e o seu lugar na sociedade". Trata-se de um "espaço contínuo de luta" (MACLURE, 1993, p. 313) que se inscreve num determinado contexto social e cultural (COLDRON; SMITH, 1999; SACHS, 2001b) e que depende do(s) entendimento(s) que os professores têm de si próprios, da sua profissão e dos contextos em que exercem a sua atividade.

Baseando-se na ideia de identidade como um princípio organizativo da vida dos professores, Maclure (1993, p. 312) analisa-a como forma de argumento, sustentando que "não deve ser entendida como uma entidade estável - algo que as pessoas possuem -, mas algo que as pessoas usam para justificar, explicar e dar sentido a si mesmos em relação a outras pessoas e aos contextos em que trabalham" (grifado no original). Sachs (2001a) defende ainda que a identidade do professor é um processo culturalmente inscrito e, por isso, aberto e mutável, que inclui determinados sentidos, valores e imagens do que significa ser professor num dado contexto.

Beijaard, Meijer e Verloop (2004), na sua revisão de 22 estudos neste domínio, identificaram um conjunto de aspetos centrais na definição da identidade profissional dos professores: (i) trata-se de um processo contínuo, dinâmico e não estável nem fixo; (ii) implica a pessoa e o contexto; (iii) integra um conjunto de sub-identidades que podem ser mais ou menos harmonizadas, que se relacionam com os diferentes contextos e relações dos professores; (iv) inclui a agência do professor enquanto elemento ativo no seu processo de desenvolvimento profissional. Trata-se, portanto, de um fenómeno multifacetado que pode incluir várias subidentidades que podem estar em sintonia ou em conflito (BEIJAARD; MEIJER; VERLOOP, 2004). 
É também este o sentido do termo presente na investigação sobre a transição de aluno a professor. Como sustenta Feiman-Nemser (2001), a construção da identidade dos professores, nomeadamente dos principiantes, implica a combinação, por vezes conflitual, entre pedaços do seu passado e a sua situação presente, surgindo associada a "um sentido de propósito em relação ao ensino e ao ser professor"' (REX; NELSON, 2004, p. 1317). Desse modo, o desenvolvimento da identidade encerra um fenómeno contínuo de integração do lado pessoal e do lado profissional no processo de tornar-se e de ser professor (BEIJAARD; MEIJER; VERLOOP, 2004), que se desenvolve na tensão entre agência (a dimensão pessoal do ensino) e estrutura (um determinado contexto social), e diz respeito ao modo como o próprio professor se vê enquanto professor e como os outros o veem, o que se prende com formas de argumentar e de redefinir uma identidade que é socialmente legitimada (COLDRON; SMITH, 1999).

Por outro lado, a literatura tem enfatizado de modo crescente o papel da formação na construção da identidade, embora a evidência empírica seja escassa (SCHEPENS; AELTERMAN; VLERICK, 2009). Como destaca Bullough (1997, p. 21), "a identidade do professor - as crenças dos professores principiantes acerca do ensino, da aprendizagem e de si próprios enquanto professores - é fundamental para a formação de professores; constitui a base para a formação de sentido e a tomada de decisão [...]. A formação de professores deve, portanto, começar por explorar o teaching self".

Nessa medida, a investigação sobre a identidade dos professores constitui um elemento importante para a formação docente e para os formadores de professores no sentido de apoiar melhor os alunos em formação na compreensão de si próprios enquanto professores (KORTHAGEN, 2004). A formação da identidade é influenciada por conceções e expectativas sobre o que um professor deve saber e fazer (BEIJAARD; MEIJER; VERLOOP, 2004), encerrando a dupla transação entre a dimensão biográfica e relacional (LOPES; PEREIRA, 2012). Assim, os padrões e expetativas sociais podem conflituar com o desejo pessoal dos professores e a com a sua experiência do que é um bom ensino (KORTHAGEN, 2004; BEIJAARD; MEIJER; VERLOOP, 2004).

Desse modo, a formação de professores, numa abordagem realista defendida por Korthagen (2009), centra-se na ajuda e apoio aos alunos em formação para "se tornarem" bons professores, envolvendo a mudança pessoal e profissional, e não em "saber" sobre o ensino (SCHEPENS; AELTERMAN; VLERICK, 2009). Para tal, é fundamental dar atenção às crenças e teorias implícitas dos alunos que, para Sugrue (1997), se formam através de uma multiplicidade de fatores tais como: família, outros significativos ou família mais alargada, aprendizagem pela observação, episódios de ensino atípicos, contexto político, tradições de ensino e arquétipos culturais e compreensões tacitamente adquiridas. É neste contexto que se reconhece a importância das biografias e das narrativas no estudo da identidade profissional, bem como do(s) contexto(s) social, cultural e profissional mais amplo(s), incluindo o contexto de formação.

No seu estudo sobre "nascer" (aspetos demográficos e traços da personalidade) ou "tornar-se" professor (baseado sobretudo na experiência), Schepens, Aelterman e Vlerick (2009) concluíram, embora com alguma precaução, que o tipo de formação de professores influencia o sentido de autoeficácia, o comprometimento e a orientação profissional, não sendo, no entanto, a variável mais importante. Para os autores, o sentido de preparação para a profissão durante a formação inicial de professores parece ser mais determinante em relação ao sentido de autoeficácia e orientação profissional, destacando-se ainda características da personalidade, bem como a motivação para entrar num curso de ensino, o que corrobora a importância da pessoa e do contexto no processo de tornar-se professor (FLORES, 2001). É, pois, importante analisar de que modo a formação de professores, nomeadamente a inicial, contribui para a formação da identidade profissional.

Flores e Day (2006) identificaram um conjunto de influências mediadoras na formação e transformação das identidades dos professores, nomeadamente a biografia pessoal, as trajetórias de formação e a identidade préensino relacionada com as imagens, as crenças e as teorias implícitas sobre o ensino e ser professor, bem como os contextos de ensino (por exemplo, a sala de aula, a cultura de escola e as lideranças escolares). Num recente estudo com 182 professores em início de carreira, Pillen, Beijaard e den Brok (2012) concluíram que as tensões na sua identidade profissional se relacionavam com um desequilíbrio entre o lado pessoal e o profissional no processo de tornar-se professor e com conflitos entre as suas aspirações e a realidade. Do mesmo modo, o estudo de Timostsuk e Ugaste (2010) demonstrou que as emoções negativas exerciam uma influência maior na formação da identidade profissional dos candidatos a professor e que os supervisores negligenciaram o papel das emoções positivas como suporte à sua aprendizagem, nomeadamente as que se relacionavam com os alunos.

Foi com o objetivo de compreender o modo como os alunos entendem as várias componentes do currículo de formação inicial de professores, com especial destaque para o lugar da prática na configuração da sua identidade profissional, que realizámos um estudo que inclui ainda a análise das suas motivações, expectativas e perspetivas futuras sobre ser professor e a profissão docente. 


\section{O ESTUDO: OBJETIVOS, OPÇÕES METODOLÓGICAS E PARTICIPANTES}

Os dados de que damos conta neste artigo decorrem de um projeto de investigação mais vasto que procura responder às seguintes questões: Quais são as motivações e influências dos alunos para a escolha de um curso de ensino e da profissão docente? Que crenças e perspetivas trazem consigo acerca do ensino e do ser professor? Quais são as suas expectativas em relação ao curso? De que modo se sentem preparados para exercer a profissão docente em diferentes momentos? Como avaliam as oportunidades de aprendizagem profissional no contexto da formação inicial de professores? Como se veem enquanto professores e quais são as suas perspectivas futuras no exercício da profissão docente?

Os dados foram recolhidos junto de alunos que frequentam/frequentaram cursos de Mestrado em Ensino na Universidade do Minho, uma vez que o grau de mestre constitui a habilitação profissional necessária para o exercício da profissão docente em Portugal. O DecretoLei no 43/2007, de 22 de fevereiro, define as condições necessárias para a obtenção de habilitação profissional para a docência, valorizando-se, de modo especial, a dimensão do conhecimento disciplinar, a fundamentação da prática de ensino na investigação e a iniciação à prática profissional. De acordo com o referido diploma, a formação inicial de professores integra as seguintes componentes: (i) formação educacional geral; (ii) didáticas específicas; (iii) iniciação à prática profissional; (iv) formação cultural, social e ética; (v) formação em metodologias de investigação educacional e (vi) formação na área de docência.

A recolha de dados foi realizada com base em questionários $^{1}$ e narrativas escritas iniciais e finais, bem como em testemunhos e relatos escritos sobre as suas experiências enquanto alunos na escola e na universidade, nomeadamente sobre a decisão de ser professor, as motivações e perspetivas sobre o ensino enquanto profissão, sobre o que significa ser professor, sobre o(a) professor(a) que mais os marcou e sobre o curso que frequentam/frequentaram, incluindo a redação de cartas dirigidas a futuros candidatos a um curso de ensino sobre a sua experiência na formação inicial. Neste artigo, baseamo-nos apenas em dados recolhidos através de narrativas escritas por 47 alunos no final do curso de Mestrado em Ensino em 2011 e 2012. Em relação aos participantes, 37 são do sexo feminino e têm idades compreendidas entre os 22 e os 45 anos.

$\mathrm{O}$ uso das narrativas permite explicitar e refletir sobre crenças, teorias implícitas e experiências e sobre a história de vida dos participantes, pois "ao dispor os dados de experiências de vida sob a forma de uma história, os indivíduos são obrigados a refletir sobre essas experiências, a selecionar os aspetos mais relevantes e a ordená-los num todo coerente. É este processo de reflexão e de "atribuir significado" fora da experiência que faz das narrativas um recurso pleno de sentido" (ELLIOT, 2005, p. 24).

Este método tem-se revelado interessante e eficaz do ponto de vista da explicitação e questionamento das representações acerca do processo de tornar-se e ser professor e do modo como os futuros professores dão sentido às suas experiências de aprendizagem, quer na universidade, quer na escola no período de estágio. Como sustentam Hollway e Jefferson (2000), as melhores pistas para narrativas convidam a falar de períodos e situações específicas, em vez de colocarem questões sobre a sua vida num longo período de tempo. Segundo Doyle e Carter (2003), o uso das narrativas tem possibilitado a emergência de importantes inovações na pedagogia da formação de professores, tais como o estudo de casos e a escrita de narrativas pessoais. Por outro lado, como sustentam Beijaard, Meijer e Verloop (2004, p. 123), a identidade "é formada e reformada pelas histórias que contamos e nas quais nos baseamos na nossa comunicação com os outros". Assim, para Clandinin, Pushor e Orr (2007), é necessário atender às dimensões temporal, social e espacial na utilização desta abordagem metodológica, aspetos que também são aplicáveis no contexto deste estudo.

No processo de análise, adotamos o método indutivo, tendo os temas substantivos sido definidos à medida que emergiam dos dados, de acordo com duas fases: uma análise vertical (MILES; HUBERMAN, 1994) de cada uma das narrativas de cada um(a) dos(das) participantes; uma análise horizontal ou comparativa com recurso ao método da "análise comparativa constante" (GLASER; STRAUSS, 1967) no sentido de identificar temas comuns e distintivos. Neste texto, damos conta dos principais temas emergentes de uma análise preliminar das narrativas, nomeadamente quanto às experiências de aprendizagem profissional mais importantes, bem como às componentes e aos momentos mais marcantes no processo de aprender a ensinar.

\section{EXPERIÊNCIAS DE APRENDIZAGEM PROFISSIONAL MAIS SIGNIFICATIVAS}

Quando questionados sobre as experiências de aprendizagem profissional mais significativas, os participantes identificaram o estágio, as metodologias de ensino e de aprendizagem durante o curso de formação, os conteúdos ligados à sua área disciplinar e outras competências transversais (Quadro 1). 
Quadro 1 - Experiências de aprendizagem profissional mais significativas

\begin{tabular}{|l|c|}
\hline & f \\
\hline Estágio & 20 \\
\hline Metodologias de Ensino e de Aprendizagem & 13 \\
\hline Conteúdos disciplinares & 11 \\
\hline Competências transversais & 6 \\
\hline
\end{tabular}

O estágio é visto pelos participantes como uma componente-chave do seu processo de aprender a ensinar, uma vez que lhes possibilita o contacto com escolas e alunos reais, constituindo ainda uma oportunidade decisiva de aprendizagem sobre "o que significa, de facto, ser professor" (Participante 3). Não obstante as dificuldades sentidas durante o estágio, que, em grande parte, se devem ao facto de os alunos terem, ao mesmo tempo, de frequentar diferentes módulos na universidade, os participantes sublinham as aprendizagens realizadas no local de trabalho, nomeadamente lidar com os alunos na sala de aula, saber como eles aprendem e se comportam, identificar as suas dificuldades de aprendizagem, entre outros aspetos, o que lhes permitiu o confronto entre a teoria e a prática, uma das questões-chave na formação de professores. Estes dados corroboram trabalhos empíricos anteriores sobre as potencialidades do estágio enquanto espaço de aprendizagem profissional (AL-HASSAN; AL-BARAKAT; AL-HASSAN, 2012):

As aprendizagens mais significativas que realizei aconteceram durante o estágio quando pude confrontar a teoria com a prática. Senti que o estágio foi uma experiência de aprendizagem fundamental para a minha prática profissional futura. (Participante 19)

O estágio foi a aprendizagem mais importante porque tive oportunidade de conhecer a realidade da escola e de receber apoio e assistência na escola, o que para mim foi mais útil do que o que aprendi na universidade. (Participante 26)

Durante o estágio aprendi muito. Mas poder ensinar foi a mais importante. Aprendemos pela prática e só se é professor na prática. Poder trocar ideias com professores experientes foi também muito importante para mim. (Participante 33)

Os participantes valorizam a partilha e a aprendizagem com outros professores na escola reiterando a importância decisiva da prática e da aprendizagem no local de trabalho no processo de tornar-se professor. Também reiteram o apoio e a orientação que receberam durante o estágio, apesar de alguns reconhecerem que há ainda aspetos a melhorar. Estes resultados corroboram investigações anteriores que mostraram que o contributo do estágio enquanto experiência de aprendizagem profissional depende da qualidade da supervisão, do trabalho em equipa e do apoio (FLORES, 2006; FLORES; DAY, 2006). Por outro lado, os participantes neste estudo apresentaram algumas sugestões para melhorar o programa de formação, nomeadamente uma melhor articulação entre as suas várias componentes incluindo o estágio, potenciar o contributo dos módulos durante o estágio e a sua mobilização para o projeto pedagógico, mais tempo para o estágio, melhor articulação entre os elementos de avaliação tais como o portefólio e o relatório final, os quais, para alguns alunos, se sobrepõem.

Estes resultados confirmam dados anteriores obtidos através de um questionário junto dos alunos, professores cooperantes, supervisores e formadores de professores, que apontam para um conjunto de problemas, nomeadamente a falta de tempo e de condições para o desenvolvimento do projeto pedagógico, coordenação insuficiente entre as várias componentes do estágio e entre os docentes da universidade, falta de relevância de alguns módulos para a análise dos contextos pedagógicos e para o desenvolvimento de competências profissionais e falta de adequação dos métodos de avaliação nalguns módulos e seminários (VIEIRA, 2010/ 2011/2012).

Os participantes neste estudo também reconhecem a relevância das componentes relacionadas com as metodologias de ensino e de aprendizagem e sublinham, em particular, o conhecimento e as competências que desenvolveram, tais como planificação, estratégias de ensino, processos de aprendizagem, motivação dos alunos, comportamento dos alunos, entre outros. Referem ainda como relevante a aquisição do conhecimento do conteúdo disciplinar:

Aprendi sobre como usar diferentes metodologias de ensino, como refletir sobre diferentes aspetos da aprendizagem da língua espanhola. A partilha de experiências com a docente, bem como conhecer e refletir sobre o comportamento dos alunos foram aspetos muito relevantes para mim como futura professora. (Participante 22)

Acho que a componente mais importante da minha formação tem a ver com as estratégias de ensino e de aprendizagem na Matemática. Aprender diferentes métodos de ensino na teoria e na prática (especialmente durante o estágio) farão de mim um melhor professor de modo a ensinar os alunos a serem cidadãos ativos e interessados na aprendizagem da Matemática. (Participante 44)

Das narrativas dos participantes emergem ainda as competências transversais, o uso das tecnologias 
de informação e comunicação na sala de aula, o desenvolvimento da reflexão crítica e a autoavaliação como aprendizagens mais significativas.

A reflexão crítica sobre o trabalho desenvolvido não só em termos de aspetos negativos, mas também de aspetos fortes foi uma experiência de aprendizagem importante para mim. (Participante 5)

As aprendizagens mais importantes foram a aquisição de competências de comunicação na língua espanhola bem como o desenvolvimento da reflexão crítica contínua sobre práticas pedagógicas alternativas para motivar os alunos. Os exercícios pragmáticos sobre estratégias orais para interagir com os alunos permitiram-me compreender o modo de desenvolver metodologias centradas nos alunos. De facto, usar uma determinada metodologia anos e anos sem interrupção e sem tempo para refletir faz de nós professores que se habituam a um processo mecânico que precisa de ser reinventado sempre. Assim, a reflexão foi, sem dúvida, uma das aprendizagens mais cruciais para mim em termos de crescimento pessoal e profissional. (Participante 28).

\section{COMPONENTES E MOMENTOS MAIS IMPORTANTES DO PROCESSO DE TORNAR-SE PROFESSOR}

Os participantes foram ainda questionados sobre as componentes e os momentos mais marcantes do processo de apender a ensinar durante o curso de formação. As categorias mais referidas prendem-se com o conteúdo do currículo de formação, o estágio, o papel dos formadores de professores, a estrutura do curso e outros aspetos organizacionais do curso e ainda as metodologias de ensino e de aprendizagem (Quadro 2).

Quadro 2 - Aspetos mais marcantes na formação inicial

\begin{tabular}{|l|c|}
\hline & f \\
\hline Conteúdo do currículo & 41 \\
\hline Estágio & 36 \\
\hline Papel dos formadores de professores & 23 \\
\hline Estrutura e organização do curso & 20 \\
\hline Metodologias de ensino e de aprendizagem & 15 \\
\hline
\end{tabular}

De modo geral, os alunos referem a adequação e a relevância das disciplinas e módulos do curso como aspetos positivos no seu processo de aprender a ensinar. Contudo, também assinalam, nalguns casos, a falta de articulação entre algumas disciplinas, a falta de relevância de alguns módulos, a discrepância entre a teoria e a prática e a sobreposição de conteúdos.
Quanto ao estágio, a vertente prática, a interação entre os supervisores e os professores cooperantes, a observação de aulas, a oportunidade de ensinar, a interação com os alunos, o contacto com a realidade e o desenvolvimento de competências surgem como dimensões mais importantes do seu processo de aprender a ensinar. No entanto, a duração reduzida do estágio, a falta de tempo, a falta de articulação entre a universidade e a escola, as restrições no desenvolvimento do projeto pedagógico, a falta de coordenação entre os vários departamentos, supervisores e coordenadores de estágio, a ausência de articulação entre os módulos do estágio e as necessidades dos alunos durante a prática pedagógica estão entre os aspetos mais negativos referidos pelos participantes quando aludem à componente do estágio como decisiva do seu percurso formativo. Também na literatura o estágio é reconhecido como componente importante no processo de aprender a ensinar, mas não existe consenso quanto aos objetivos, às visões da educação e da aprendizagem profissional que lhe estão subjacentes, às estratégias e competências profissionais a desenvolver, ao papel dos vários intervenientes e ao lugar da prática em relação às outras componentes dos programas de formação (FLORES; VIEIRA; FERREIRA, no prelo).

No meu processo de aprender a ensinar destaco a interação com os meus colegas e a reflexão crítica com os meus supervisores e professores cooperantes. (Participante 5)

No segundo ano, para mim o mais importante foi a possibilidade de observar as aulas dos professores cooperantes e ensinar um grupo de alunos, o que me permitiu perceber como funciona a prática pedagógica. (Participante 21)

Para mim o mais importante foi a oportunidade de ensinar alunos reais e ser uma referência positiva para eles. (Participante 46)

No segundo ano temos muitos trabalhos práticos sem qualquer relação entre eles nem com o projeto de intervenção, o que para mim foi o mais difícil este ano. Ficou pouco tempo para desenvolver o projeto. (Participante 47)

Em relação ao papel dos formadores de professores, os participantes no estudo destacam a sua qualidade, a orientação e o apoio que lhes proporcionaram, o seu comprometimento com o processo de formação, a sua disponibilidade e o modo como interagiam com os estudantes. Todavia, também reconhecem que alguns formadores não demonstram qualidade, destacando a sua falta de empenho, a falta de apoio e de articulação entre eles e referem-se ainda ao modo como implementam a avaliação nas suas disciplinas ou módulos. 
A interação com alguns formadores de professores foi muito importante. Ensinaram-nos aspetos relevantes para a nossa formação e mostraram-nos como fazer mais e melhor em relação à investigação. (Participante 3)

Como aspeto importante, destaco o comprometimento e o apoio total por parte dos formadores durante as unidades curriculares. (Participante 33)

O mais importante para mim foi a boa orientação dada pelos formadores e pelos professores e a oportunidade de partilhar experiências. (Participante 41)

Por parte de alguns docentes não houve orientação e não tinham critérios de avaliação. (Participante 17)

Por vezes há muita exigência por parte de alguns formadores que não são exigentes consigo mesmos e com o que fazem. (Participantes 20)

Relativamente às metodologias de ensino e de aprendizagem, os participantes destacam a diversidade de métodos e a componente investigativa e reflexiva do processo de formação. Contudo, reconhecem a inadequação de alguns métodos de ensino e a falta de autonomia por parte dos alunos.

O mais importante foi para mim poder refletir didática e metodologicamente sobre questões ligadas ao ensino e ao conteúdo da disciplina que vou ensinar. (Participante 21)

Penso que os aspetos menos positivos foram a falta de informação e algumas inconsistências por parte da coordenação e a falta de autonomia dos alunos. (Participante 33)

Finalmente, quanto à estrutura e aos aspetos organizacionais, os alunos futuros professores destacam as boas instalações, os horários e a carga horária, mas também admitem que a estrutura do curso pode ser melhorada, assim como algumas questões ligadas à gestão dos horários e à carga horária, sobretudo no segundo ano.

\section{CONSIDERAÇÕES FINAIS}

Como formadora de professores, uma das minhas preocupações prende-se com a coerência entre o que ensino e como ensino e as competências, conhecimentos e atitudes que pretendo desenvolver nos meus alunos. No fundo, trata-se de refletir sobre as seguintes questões: O que fazem os alunos nas minhas aulas? Que tipo de experiências de aprendizagem lhes proporciono? Qual é a relevância e o contributo do meu ensino e do meu trabalho com eles durante um semestre para o seu desenvolvimento enquanto futuros professores? Assim, assumem particular importância estratégias que potenciem a reflexão crítica por parte dos alunos sobre o seu processo de formação e sobretudo sobre as suas crenças e teorias implícitas sobre o ensino e sobre o processo de tornar-se e ser professor. Por outras palavras, trata-se da formação da identidade profissional e da reflexão sobre a construção do conhecimento profissional num "processo reflexivo e crítico (pessoal) sobre o que significa ser professor e sobre os propósitos e valores implícitos nas próprias ações e nas instituições em que se trabalha" (FLORES, 2004, p. 139).

A literatura aponta para a formação da identidade como parte do processo de aprender a ensinar e, em particular, para a importância do contexto em que se desenrola o processo de aprender a ensinar e o processo de formação (SCHEPENS; AELTERMAN; VLERICK, 2009) no sentido de apoiar a transformação da identidade na formação inicial de professores (TIMOSTSUK; UGASTE, 2010).

De facto, o desenvolvimento da identidade profissional constitui um elemento decisivo na formação de professores no sentido de proporcionar a tomada de consciência e a reflexão sobre o modo como os alunos se veem enquanto professores e o tipo de professores que aspiram vir a ser, bem como sobre a natureza e lugar da profissão docente tendo em conta o contexto político, social, cultural, geográfico e económico em que ela se inscreve. Como referem Beijaard, Meijer e Verloop (2004), o estudo da formação da identidade profissional é fundamental para a compreensão do que significa ser professor hoje num contexto de mudanças rápidas a que o professor tem de dar resposta. Trata-se, portanto, de compreender as crenças e as motivações para entrar no ensino (e para aí permanecer) assim como as tensões interiores e o modo como os alunos futuros professores dão sentido às suas experiências de aprendizagem na universidade e na escola. Desse modo, é possível identificar e compreender as tensões, continuidades e descontinuidades no processo de desenvolvimento da identidade profissional durante a formação inicial incluindo as experiências de aluno(a) na escola e na universidade, bem como no estágio e, posteriormente, no exercício autónomo de funções docentes.

Estudos anteriores revelam as contradições entre as crenças e as práticas, bem como os conflitos interiores das identidades em mudança - de aluno a futuro professor e de futuro professor a professor principiante e ainda de principiante a experiente (FLORES, 2001; SMAGORINSKY et al., 2004; FLORES, 2006; FLORES; DAY, 2006; LAMOTE; ENGELS, 2010; FLORES, 2013) e sugerem que a influência dos cursos de formação inicial pode ser potenciada através de um maior enfoque nas oportunidades para experienciar e refletir sobre a 
biografia pessoal e os contextos culturais da escola para que as tensões entre eles possam ser compreendidas de modo mais aprofundado e consistente (FLORES; DAY, 2006).

Esses dados são corroborados por estudos posteriores, nomeadamente Timostsuk e Ugaste (2010), ao enfatizarem a importância dos aspetos sociais da aprendizagem e a ligação entre formação de professores e sociedade. De igual modo, Lamote e Engels (2010) indicam que os alunos com experiência de ensino desenvolvem uma visão mais "realista" da aprendizagem e do ensino do que aqueles que ainda não passaram por ela e identificaram diferenças em termos de género: os futuros professores tendem a atribuir mais importância à disciplina na sala de aula ao passo que as futuras professoras se centram mais no envolvimento dos alunos.

Torna-se, assim, fundamental compreender (e questionar) crenças, valores e imagens pessoais sobre o ensino e sobre o que significa tornar-se (e ser) professor, bem como sobre o próprio processo de formação e de (re)construção de saberes, através da reflexão e da indagação em articulação com a prática com vista ao desenvolvimento e compreensão da identidade profissional. Por outras palavras, durante a formação inicial, em articulação com as escolas onde os alunos realizam as práticas de ensino, é essencial proporcionar oportunidades para que os alunos se envolvam se forma mais direta num processo crítico e reflexivo sobre o processo de tornar-se professor. Este aspeto é ainda mais premente no contexto atual da formação de professores em Portugal no sentido de perceber o impacto dos novos contextos (e dos "novos" curricula) de formação para a melhoria da sua qualidade, bem como compreender e refletir sobre o tipo de professor que se está a formar no âmbito do novo quadro legal e institucional (FLORES, 2011), o que, implica necessariamente, a análise das estratégias e oportunidades de construção da identidade profissional durante a formação inicial.

\section{REFERÊNCIAS}

AL-HASSAN, Omayya; AL-BARAKAT, Ali; AL-HASSAN, Yazid. Pre-service teachers' reflections during field experiences. Journal of Education for Teaching, v. 38, n. 4, p. 419-434, 2012.

BEIJAARD, Douwe; MEIJER, Paulein; VERLOOP, Nico. Reconsidering research on teachers' professional identity. Teaching and Teacher Education, n. 20, p. 107-128, 2004.

BULLOUGH Robert V. Practicing theory and theorizing practice. In: LOUGHRAN, J.; RUSSELL, T. (Ed.). Purpose, passion and pedagogy in teacher education. London: FalmerPress, 1997. p. 13-31.

CALDERHEAD, James; SHORROCK, Susan. Understanding teacher education: case studies in the professional development of beginning teachers. London: Falmer Press, 1997.
CLANDININ, D. Jean.; PUSHOR, Debbie; ORR, Anne Murray. Navigating sites for narrative inquiry. Journal of Teacher Education, v. 58, n. 1, p. 21-35, 2007. http://dx.doi. org/10.1177/0022487106296218

COLDRON, John; SMITH, Robin. Active location in teachers' construction of their professional identities. Journal of Curriculum Studies, v. 31, n. 6, p. 711-726, 1999. http:// dx.doi.org/10.1080/002202799182954

DAY, Christopher et al. The personal and the professional selves of teachers: stable and unstable identities. British Educational Research Journal, v. 32, n. 4, p. 601-616, 2006.

DOYLE, Walter; CARTER, Kathy. Narrative and learning to teach: implications for teacher-education curriculum. Journal of Curriculum Studies, v. 35, n. 2, p. 129-137, 2003. http:// dx.doi.org/10.1080/0022027022000023053

ELLIOTT, John. Using narrative in social research: qualitative and quantitative approaches. London: Sage, 2005.

FEIMAN-NEMSER, Sharon. From preparation to practice: designing a continuum to strengthen and sustain teaching. Teachers College Record, v. 103, n. 6, p.1013-1055, 2001. http://dx.doi.org/10.1111/0161-4681.00141

FLORES, Maria Assunção. Curriculum of initial teacher education in Portugal: new contexts, old problems. Journal of Education for Teaching (special issue), v. 37, n. 4, p. 461-470, 2011.

FLORES, Maria Assunção. Person and context in becoming a new teacher. Journal of Education for Teaching, v. 27, n. 2, p. 135-148, 2001.http://dx.doi.org/10.1080/02607470120067882

FLORES, Maria Assunção. Dilemas e desafios na formação de professores. In: MORAES, Maria Célia; PACHECO, José Augusto; EVANGELISTA, Maria Olinda (Org.). Formação de professores: perspectivas educacionais e curriculares. Porto: Porto Editora, 2004. p. 127-160.

FLORES, Maria Assunção. Being a novice teacher in two different settings: struggles, continuities, and discontinuities. Teachers College Record, v. 108, n. 10, p. 2021-2052, 2006. http://dx.doi.org/10.1111/j.1467-9620.2006.00773.x

FLORES, Maria Assunção. Be(com)ing a teacher in challenging circumstances: sustaining commitment or giving up in Portugal? In: CRAIG, C.; MEIJER, P.; BROEKEMANS, J. (Ed.). From teacher thinking to teaching: the evolution of a research community. Advances in Research on Teaching, v. 19, p. 405-425, New York: Emerald Publishers, 2013. http://dx.doi. org/10.1108/S1479-3687(2013)0000019022

FLORES, Maria Assunção; DAY, Christopher. Contexts which shape and reshape new teachers' identities: a multi-perspective study. Teaching and TeacherEducation, v. 22, n. 2, p. 219-232, 2006. http://dx.doi.org/10.1016/j.tate.2005.09.002

FLORES, Maria Assunção; VIEIRA, Flávia; FERREIRA, Fernando Ilídio. Formação inicial de professores em Portugal: problemas, desafios e o lugar da prática nos mestrados em ensino pós-Bolonha. In: BORGES, Maria Célia; AQUINO, Orlando Fernández. (Ed.). A formação inicial de professores em diferentes contextos: políticas, práticas e perspectivas. Minas Gerais, Brasil: EDUFU. (no prelo).

GLASER, Barney G.; STRAUSS, Anselm. L. The Discovery of Grounded Theory: Strategies for Qualitative Research. Chicago: Aldine, 1967. 
HAUGE, Trond. Student teachers' struggle in becoming professionals: hopes and dilemmas in teacher education. In: DAY, Christopher. et al. (Ed.). The life and work of teachers: international perspectives in changing times. London: Falmer Press, 2000. p. 159-172.

HOLLWAY, Wendy.; JEFFERSON, Tony. Doing qualitative research differently: free association, narrative and the interview method. London: Sage, 2000.

KELTCHTERMANS, Geert. Teachers' emotions in educational reform: self-understanding, vulnerable commitment and micropolitical literacy. Teaching and Teacher Education, n. 21, p. 995-1006, 2005.

KORTAGEN, Fred. A prática, a teoria e a pessoa na aprendizagem profissional ao longo da vida. In: FLORES, Maria Assunção; SIMÃO, Ana Maria Veiga (Org.). Aprendizagem e desenvolvimento profissional de professores: contextos e perspectivas. Mangualde: Pedago, 2009. p. 39-60.

KORTAGEN, Fred. In search of the essence of a good teacher: towards a more holistic approach in teacher education. Teaching and Teacher Education, v. 20, p. 77-79, 2004. http://dx.doi. org/10.1016/j.tate.2003.10.002

LAMOTE, Carl.; ENGELS, Nadine. The development of student teachers' identity. European Journal of Teacher Education, v. 33, n. 1, p. 3-18, 2010. http://dx.doi.org/ $10.1080 / 02619760903457735$

LOPES, Amélia; PEREIRA, Fátima. Everyday life and everyday learning: the ways in which pre-service teacher education curriculum can encourage personal dimensions of teacher identity. European Journal of Teacher Education, v. 35 , n. 1, p. 17-38, 2012. http://dx.doi.org/10.1080/0261976 8.2011 .633995

MACLURE, Maggie. Arguing for yourself: identity as an organizing principle in teachers' jobs and lives. British Educational Research Journal, v. 19, n. 4, p. 311-322, 1993. http://dx.doi.org/10.1080/0141192930190401

MILES, Mathew; HUBERMAN, Michael. Qualitative data analysis: an expanded sourcebook. 2. ed. Thousand Oaks, CA: Sage, 1994.

NÓVOA, António. Os professores e as histórias da sua vida. In: NÓVOA, António. (Org.). Vidas de professores. Porto: Porto Editora, 1992. p. 11-30.

PILLEN, Marieke; BEIJAARD, Douwe; BROK, Perry den. Tensions in beginning teachers' professional identity development, accompanying feelings and coping strategies. European Journal of Teacher Education, i-first, p. 1-21, 2012.
PORTUGAL. Decreto-Lei n. 43/2007, de 22 de fevereiro. Aprova o regime jurídico da habilitação profissional para a docência na educação pré-escolar e nos ensinos básico e secundário. Rectificado pelo Ministério da Educação em 22 fev. 2007, n. 38, série I. Diário da República Eletrónico. Disponível em: <http://www.dges.mctes.pt/NR/rdonlyres/84F15CC85CE1-4D50-93CF-C56752370C8F/1139/DL432007.pdf $>$. Acesso em: 20 dez. 2013.

REX, Lesley A.; NELSON, Mathew. How teachers' professional identities position high-stakes test preparation in their classrooms. Teachers College Record, v. 106, n. 6, p. 1288-1331, 2004. http://dx.doi.org/10.1111/j.1467-9620.2004.00380.x

SACHS, Judith. Learning to be a teacher: teacher education and the development of professional identity. Conferência convidada proferida no Congresso da ISATT, Faro, Portugal, setembro 21-25, $2001 \mathrm{a}$.

SACHS, Judith. Teacher professional identity: competing discourses, competing outcomes. Journal of Education Policy, v. 16 , n. 2, p. 148-161, 2001b.

SCHEPENS, Annemie.; AELTERMAN, Antonia.; VLERICK, Peter. Student teachers' professional identity formation: between being born as a teacher and becoming one. Educational Studies, v. 35, n. 4, p. 361-378, 2009. http://dx.doi. org/10.1080/03055690802648317

SMAGORINSKY, Peter. et al. Tensions in learning to teach. Accommodation and the development of a teaching identity, Journal of Teacher Education, v. 55, n. 1, p. 8-24, 2004. http:// dx.doi.org/10.1177/0022487103260067

SUGRUE. Ciaran. Student teachers' lay theories and teaching identities: their implications for professional development. European Journal of Teacher Education, n. 20, p. 213-225, 1997.

TIMOSTSUKI, Inge; UGASTE, Aino. Student teachers' professional identity. Teaching and Teacher Education, v. 26, n. 8 , p. 1563-1570, nov. 2010. http://dx.doi.org/10.1016/j.tate. 2010.06.008

VIEIRA, Flávia. Balanço final do estágio. Documentos produzidos no âmbito da coordenação do Estágio dos Mestrados em Ensino da Universidade do Minho. 11 dez. 2010.

\section{NoTA}

1 O questionário utilizado resultou, com a devida autorização, de uma adaptação para língua portuguesa do instrumento elaborado no âmbito do projeto Teachers for a New Era, do Boston College, EUA.

Artigo recebido em novembro 2013.

Aprovado em janeiro 2014. 